\title{
DDR-Type Zeolite Membrane Synthesis, Modification and Gas Permeation Studies
}

\author{
Shaowei Yang, Zishu Cao, Antonios Arvanitis, Xinhui Sun, Zhi Xu, Junhang Dong* \\ Department of Chemical Engineering, University of Cincinnati, Cincinnati, Ohio 45221
}

\begin{abstract}
:
DDR-type zeolite membrane was synthesized on porous $\alpha$-alumina substrate by hydrothermal treatment of a ball-milled Sigmal-1 crystal seed layer in an aluminum-free precursor solution containing 1-Adamantylamine as the structure directing agent. The as-synthesized DDR zeolite membranes were defect-free but the supported zeolite layers were susceptible to crack development during the subsequent high-temperature SDA removal process. The cracks were effectively eliminated by the liquid phase chemical deposition method using tetramethoxysilane as the precursor for silica deposits. The modified membrane was extensively studied for $\mathrm{H}_{2}, \mathrm{He}, \mathrm{O}_{2}, \mathrm{~N}_{2}, \mathrm{CO}_{2}, \mathrm{CH}_{4}$, and $i-\mathrm{C}_{4} \mathrm{H}_{10}$ pure gas permeation and $\mathrm{CO}_{2} / \mathrm{CH}_{4}$ mixture separation. At $297 \mathrm{~K}$ and 2-bar feed gas pressure, the membrane achieved a $\mathrm{CO}_{2} / \mathrm{CH}_{4}$ separation factor of $\sim 92$ for a feed containing $90 \% \mathrm{CO}_{2}$, which decreased to 62 for a feed containing $10 \%$ $\mathrm{CO}_{2}$ with the $\mathrm{CO}_{2}$ permeance virtually unchanged at $\sim 1.8 \times 10^{-7} \mathrm{~mol} / \mathrm{m}^{2} \cdot \mathrm{s} \cdot \mathrm{Pa}$ regardless of the feed composition. It also exhibited an $\mathrm{O}_{2} / \mathrm{N}_{2}$ permselectivity of 1.8 at $297 \mathrm{~K}$. The gas permeation behaviors of the current aluminum-containing DDR type zeolite membrane are generally in good agreement with the findings in both experimental and theoretical studies on the pure-silica DDR membranes in recent literature.
\end{abstract}

Keywords: DDR, Sigma-1, zeolite membrane, modification, gas separation

\footnotetext{
* Corresponding author: Phone: +1 (513) 556-3992; Fax: +1 (513) 556-3473; Email: Junhang.dong@uc.edu
} 


\section{Introduction}

The Deca-Dodecasil 3 Rhombohedral (DDR) zeolite has elliptical pore openings defined by 8member ring windows with an effective size of $0.36 \times 0.44 \mathrm{~nm}$, which is suitable for separating many small molecule gases. Polycrystalline pure-silica DDR-type zeolite membranes was first synthesized by Tomita et al. [1] on macroporous alumina substrates and demonstrated for separating molecules of small sizes. Compared to other types of 8-member ring small pore zeolite membranes, such as the SAPO-34 (0.38 nm), LTA $(0.41 \mathrm{~nm})$, and T-type zeolite $(0.41 \mathrm{~nm})$, etc., the highly siliceous DDR zeolite membrane has the advantages of better thermal and chemical stabilities and tolerance to presence of water vapor [1,2]. The DDR zeolite membranes thus have been one of the focuses in developing ultramicroporous membranes for separating small gases, which are important to the energy industry. In the past decade, the DDR zeolite membranes have been demonstrated both experimentally and theoretically to have attractive potential for effective separations of $\mathrm{CO}_{2}, \mathrm{CH}_{4}, \mathrm{H}_{2}, \mathrm{O}_{2}$, and $\mathrm{N}_{2}$, etc. [1-7]. However, despite the strong practical and theoretical interests, the successful synthesis of high quality DDR zeolite membranes has been quite limited. The main challenges in DDR zeolite membrane synthesis include the difficulty in avoiding formation of DOH and SGT impurity phases, lengthy and sophisticated preparation procedures, and susceptibility to crack formation during high temperature removal of the structure directing agent (SDA) from the zeolitic pores.

To date, most of the DDR membranes appeared in the literature, which exhibited good gas permeation selectivity and performance reproducibility, were fabricated by Tomita, Himeno, and coworkers at NGK Insulators, Ltd. (Japan) $[1-4,8,9]$. The synthesis of DDR zeolite membranes involved two major steps, including the first step to synthesize DDR zeolite particles for coating a seed layer on porous substrate, and the second step to hydrothermally treat the DDR seed layer in SDA-containing precursor solutions for growing the seed layer into a dense polycrystalline DDR film. The as-synthesized DDR membrane must undergo calcination to remove the SDA from zeolitic pores typically at $>700^{\circ} \mathrm{C}$. The DDR zeolite membranes made by Himeno and coworkers achieved a $\mathrm{CO}_{2}$ to $\mathrm{CH}_{4}$ separation factor of 
200 with $\mathrm{CO}_{2}$ permeance of $3.0 \times 10^{-7} \mathrm{~mol} / \mathrm{m}^{2} \cdot \mathrm{s} \cdot \mathrm{Pa}$ at room temperature and 2 bar feed pressure [2]. This membrane also exhibited pure gas permeance in the order of $\mathrm{CO}_{2}>\mathrm{H}_{2}>\mathrm{He}>\mathrm{O}_{2}>\mathrm{N}_{2}>\mathrm{CH}_{4}$, which are results of molecular sieving effect and competitive adsorption-diffusion transport mechanisms expected in the DDR pores depending on the kinetic size of the permeating gas.

There have been other reports on DDR zeolite membrane synthesis and tests for gas separation, which showed large discrepancies in separation performance. Kim et al. used the DDR-seeded secondary growth method to synthesize DDR membrane and the membrane exhibited no permeation selectivity between $\mathrm{CO}_{2}$ and $\mathrm{N}_{2}$ (i.e. selectivity 1) [10] which differs qualitatively from the values of $>10$, which were experimentally obtained by Tomita et al. [1] and theoretically predicted by Krishna et al. [7]. Bose et al. synthesized DDR membrane by sonication mediated hydrothermal reaction [11]. The resultant membrane exhibited $\mathrm{H}_{2} / \mathrm{CO}_{2}$ separation factor of $>3$ (i.e. $\mathrm{H}_{2}$-selective) at room temperature, which is also fundamentally different from the value of 0.15 - 0.3 (i.e. $\mathrm{CO}_{2}$-selective) found by molecular simulations [7]. Zheng et al. [5] reported the synthesis of DDR membranes, which exhibited largely inconsistent $\mathrm{H}_{2} / \mathrm{CO}_{2}$ separation factors varying from 2.4 to 0.7 at $298 \mathrm{~K}$. Since $\mathrm{CO}_{2}$ is highly adsorbing with relatively high diffusivity in the DDR zeolitic pores [3,6,7], the DDR membrane is anticipated to have high separation selectivity towards $\mathrm{CO}_{2}$ against the weakly adsorbing gases (e.g. $\mathrm{H}_{2}, \mathrm{He}, \mathrm{N}_{2}$, and $\mathrm{O}_{2}$, etc.) due to the blocking effect by the preferentially adsorbed $\mathrm{CO}_{2}$. The serious discrepancies of gas separation selectivity for the DDR zeolite membranes reported in literature are caused by the differences in membrane quality in terms of the presences of intercrystalline pores or cracks, impurity phases, and framework compositions.

In the polycrystalline zeolite membranes, the existence of intercrystalline spaces larger than the zeolitic pores is inherent and could drastically decrease the gas permeation selectivity especially when the separation relies on molecular sieving or size discrimination (steric effect) [12]. Additional intercrystalline gaps or cracks may form during high temperature firing for SDA removal because of mismatches of the thermal expansion coefficient between the zeolite layers and the substrates [13,14]. 
The SDA removal from the small pore DDR zeolite is accomplished at very high temperature, commonly at $>700^{\circ} \mathrm{C}$, that increases the risk of crack formation. Severe crack formation was observed in the puresilica DDR zeolite membranes by Kim et al. that likely caused the poor permselectivity for $\mathrm{CO}_{2} / \mathrm{N}_{2}$ [10]. In the past, various chemical and physical deposition techniques have been investigated for repairing cracks and minimizing intercrystalline pores in post-firing zeolite membranes, particularly for the MFItype and DDR-type zeolite membranes.

The chemical vapor deposition (CVD) of silica using silane precursors is perhaps the most extensively studied technique for repairing defects in zeolite membranes $[4,5,15,16]$. Although the CVD method, particularly when the deposits are formed by surface reactions, is apparently effective for reducing nanometer-scale defects, it may be ineffective for eliminating cracks of large sizes because excessive deposition at the zeolite's external surface could occur before the big cracks are sufficiently plugged. Another important technique for repairing defects in zeolite membranes is the liquid phase chemical deposition approach, which is often achieved by solid precipitation inside the nonzeolitic pores as results of reactions between precursors introduced through liquid phase counter diffusion from the two sides of the membrane. The precipitating solids are mostly polymeric or oligomeric hydrous metal oxides or metalloid oxides produced by hydrolysis and condensation reactions [17-19]. Zhang et al. [17] used cohydrolysis and co-condensation of tetraethoxy orthosilicate (TEOS) and (3-chloropropyl) triethoxysilane (3CP-TES) at the organic/aqueous interface for defect patching in silicalite-1 zeolite membranes, which increased the separation factor for a 50/50 n/i-butane-gas mixture from 4.4 to 35.8 after modification. Hong et al. [19] conducted the hydrolysis of TEOS, tetramethoxysilane (TMOS), or dimethoxydimethylsilane (DMDS) under flow condition for defect plugging in MFI zeolite membranes, which achieved a p-/o-xylene separation factor improvement from 2.34 to 10.84. Dong et al. [18] employed the deposition of hydrous aluminum oxide oligomers inside the intercrystalline pores of MFI zeolite membranes via counter-diffusion of $\mathrm{AlCl}_{3}$ solutions that enhanced the membrane selectivity in reverse osmosis desalination. Compared to the vapor phase operation of CVD methods, the liquid phase 
chemical deposition technique has the unique features of slower reactant diffusion, greater precursor concentration adjustability, and liquid surface tension to better control the reaction zone within the defect spaces, especially in the cases of repairing large pinholes and cracks.

In this work, we developed a DDR zeolite membrane synthesis approach using ball-milled Simga-1 crystals, an aluminum-containing structure analog of DDR zeolite, instead of the commonly employed pure-silica DDR crystals, for the seed layer. In our recent studies, the ball-milled Sigma-1 zeolite crystals were demonstrated to be very effective seeds for synthesizing DDR-type zeolite particles via the secondary growth approach $[20,21]$. The use of Sigma-1 seeds in DDR particle synthesis was found to have a number of important advantages over the conventional approach using pure-silica DDR zeolite seeds, including substantially shortened duration of the overall synthesis process, excellent product reproducibility and avoidance of impurity formation, much smaller consumption of SDA and organic agents, and simpler precursor preparation procedures and synthesis conditions [20,21], which are desirable for membrane fabrication from the practical perspective. The synthesized DDR membranes were subsequently modified by a liquid phase chemical deposition method to minimize intercrystalline spaces and repair cracks induced in the high temperature SDA removal process. The resultant membranes were evaluated by pure gas permeation for a number of practically and theoretically important small molecule gases, including $\mathrm{H}_{2}$, $\mathrm{He}, \mathrm{N}_{2}, \mathrm{O}_{2}, \mathrm{CO}_{2}, \mathrm{CH}_{4}$, and $i-\mathrm{C}_{4} \mathrm{H}_{10}$, and separation of the $\mathrm{CO}_{2} / \mathrm{CH}_{4}$ binary mixtures.

\section{Experimental}

\subsection{Materials and chemicals}

The porous $\alpha$-alumina discs made of $0.46 \mu \mathrm{m}$ diameter $\alpha$-alumina powders (SG16, Alcoa, TN) were used as membrane substrates. The alumina disc was 2-mm thick and $~ 26-\mathrm{mm}$ in diameter with porosity and average pore diameter $\left(d_{p}\right)$ of $27-30 \%$ and $0.1 \mu \mathrm{m}$, respectively. The edges of the disc were sealed by coating a dense glass film and the active membrane area after excluding the area of glass seal was $2.54 \mathrm{~cm}^{2}$. The following chemicals and materials were used in the present work: Ludox SM colloidal 
silica (30 wt. \%, Aldrich), sodium hydroxide (99.99\% trace metal basis, pellet, Sigma-Aldrich), 1adamantylamine (ADA, 97\%, Aldrich), fumed silica (0.007 $\mu \mathrm{m}$, Aldrich), ethylenediamine (EDA, 99.5\%, Fluka), and sodium aluminate (anhydrous, $\mathrm{Al}$ content as $\mathrm{Al}_{2} \mathrm{O}_{3}:$ 50-56 wt.\%, Riedel-de Haën, Germany), tetramethoxysilane (TMOS, 98\%, Sigma-Aldrich), $\mathrm{HNO}_{3}$ solution (1.0 M, Fluka), and hydroxypropyl cellulose (HPC, 99\%, Mw. 100,000, Aldrich). All chemicals were used as received without further processing. Gases used for membrane permeation tests included $\mathrm{H}_{2}$ (99.999\%), helium (99.999\%), $\mathrm{N}_{2}$ (99.999\%), $\mathrm{O}_{2}$ (99.6\%), $\mathrm{CO}_{2}$ (99.99\%), $\mathrm{CH}_{4}$ (99.999\%), and $i-\mathrm{C}_{4} \mathrm{H}_{10}$ (99.5\%). All gases were obtained from Wright Brothers, Inc. (Cincinnati, USA) and used as received.

\subsection{Sigma-1 seed-layer preparation}

The Sigma-1 zeolite crystals were synthesized by the in situ hydrothermal crystallization method following the procedure detailed in previous publications [20, 21]. The precursor solution for Sigma-1 zeolite synthesis was obtained by mixing a solution made of 2.0 g ADA, $6.6 \mathrm{~mL}$ Ludox colloidal silica and $13 \mathrm{~mL}$ DI water with another solution containing $0.108 \mathrm{~g} \mathrm{NaAlO}, 0.106 \mathrm{~g} \mathrm{NaOH}$, and $10 \mathrm{~mL} \mathrm{DI}$ water followed by $4 \mathrm{~h}$ of rigorous stirring at $50^{\circ} \mathrm{C}$. The final precursor, which was a stable sol, was transferred into a Teflon-lined autoclave equipped with a magnetic stir bar. The hydrothermal crystallization was performed in the closed autoclave under autogenous pressure at $180^{\circ} \mathrm{C}$ with moderate stirring. The duration of the hydrothermal reaction was 3 days. The resultant Sigma-1 particles were thoroughly washed by DI water and then ball-milled for 2 h at 350 rpm speed (PM 100, Restch, Germany; ф3-mm zirconia beads; stainless steel jar with magnet iron remover).

The ball-milled Sigma-1 zeolite particles was cleaned and re-dispersed into DI water and peptized with 1.0 $\mathrm{M} \mathrm{HNO}_{3}$ solution. The suspension was mixed with a solution of hydroxypropyl cellulose (HPC), which was used as drying control agent (DCA). The final colloidal suspension had a Sigma-1 solid content of 0.2 wt.\%, a pH value of 3 4, and HPC concentration of 0.2 wt.\%. This suspension was used to coat the Sigma-1 seed layer on the alumina disc by the conventional dip-coating technique. The contacting time for the dip-coating process was $5 \mathrm{~s}$. After coating the Sigma-1 seed layer, the disc 
substrate was dried in an oven at $313 \mathrm{~K}$ for 2 days and then calcined at $973 \mathrm{~K}$ for $6 \mathrm{~h}$ using heating and cooling rates of $0.5 \mathrm{~K} / \mathrm{min}$.

\subsection{DDR membrane synthesis and characterization}

The Sigma-1 seed layer was hydrothermally treated in a precursor solution to grow a polycrystalline DDR zeolite layer. The precursor solution for DDR zeolite membrane growth had a molar ratio composition of $100\left(\mathrm{SiO}_{2}\right)$ : $15(\mathrm{ADA})$ : $135(\mathrm{EDA}): 11240\left(\mathrm{H}_{2} \mathrm{O}\right): 15\left(\mathrm{Na}_{2} \mathrm{O}\right)$, which has been previously demonstrated for highly reproducible synthesis of pure DDR-type zeolite crystals using the same ballmilled Sigma-1 particles as seeds [20]. This precursor was prepared by a multistep procedure: first, a solution "A" was obtained by sequentially dissolving $\mathrm{NaOH}$ pellets and fumed silica in DI water at around $353 \mathrm{~K}$ under stirring; second, a solution "B" was prepared by mixing ADA with EDA under vigorous stirring and shaking; third, both solutions A and B were cooled to room temperature and then mixed by 5-min stirring to obtain the final precursor solution. The precursor solution was carefully poured into a Teflon-lined autoclave where a Sigma-1 seeded alumina disc was placed vertically on a stand at the bottom. The autoclave was then closed and placed in an oven where the hydrothermal reaction was performed at $433 \mathrm{~K}$ for $24 \mathrm{~h}$. After the synthesis, the disk was recovered and washed with D.I. water. The membrane was dried in an oven at $313 \mathrm{~K}$ for a day and then at $393 \mathrm{~K}$ for overnight. The dry membrane was then tested for gas tightness by pure helium permeation before calcination. The SDA (i.e. ADA molecules), which occupied the zeolitic pores, was removed by firing at $973 \mathrm{~K}$ for $6 \mathrm{~h}$ to activate the membrane. The heating and cooling rates used in the firing program were both $1 \mathrm{~K} / \mathrm{min}$.

The Sigma-1 seeded disc and the zeolite membrane were examined by X-ray diffraction (XRD, PANalytical, X'Pert Pro MPD, Netherlands) to confirm the crystal phase and purity. Scanning electron microscopy (SEM, FEI, XL30, USA) was used to observe the membrane morphology and estimate the effective thickness and the energy dispersive X-ray spectroscopy (EDS, Ametek, Octane Super, USA) was employed to determine the elemental compositions (e.g., $\mathrm{Si} / \mathrm{Al}$ and $\mathrm{Na} / \mathrm{Al}$ ratios) at different locations along the thickness of the zeolite layer. 


\subsection{Membrane modification}

The DDR zeolite membranes after high temperature SDA removal underwent a defect repair step using the liquid phase chemical deposition method, which was similar to those reported in the literature $[17,19]$. The membrane modification was accomplished by the following procedure: first, the substrate side of the membrane was fully soaked with water without directly wetting the zeolite membrane surface and the excessive water on the substrate surface was wiped off using powderless cleaning tissues; second, the membrane disc was immediately mounted in a permeation cell and the zeolite membrane surface was strongly swept by compressed air for about $10 \mathrm{~s}$ to remove any liquid water possibly remaining on the surface; third, the cell chamber on the zeolite membrane side was filled with TMOS liquid and the chamber on the back (substrate) side was filled with D.I. water; finally, the liquid-filled membrane cell was kept static with the zeolite membrane surface facing upward for $2 \mathrm{~h}$ for the hydrolysis and deposition to take place inside the intercrystalline spaces and cracks by liquid phase counter diffusion of TMOS and water. The liquids were then drained from both chambers and both sides of the membrane were swept by dry air to remove the excessive liquid. The membrane disc was subsequently dried at $333 \mathrm{~K}$ for 1 day followed by further drying at $473 \mathrm{~K}$ for overnight. The above modification process was repeated once to ensure the elimination of large cracks and minimization of defect pores.

\subsection{Gas permeation measurements}

All membranes were first tested for helium permeation prior to SDA removal after overnight drying at $393 \mathrm{~K}$. Because the zeolitic pores were occupied by SDA molecules before firing, a completely defect-free membrane should be impermeable to any gases. The pre-activation membranes measured pure helium permeance in the order of $10^{-10} \mathrm{~mol} / \mathrm{m}^{2} \cdot \mathrm{s} \cdot \mathrm{Pa}$ or less were considered to be of good quality and used for further studies in this work. After the SDA removal, the membrane was degassed in the permeation cell by vacuuming at $453 \mathrm{~K}$ for $12 \mathrm{~h}$ prior to each gas permeation experiment. The permeance of pure gases was measured by the transient permeation method [22] at 297, 333, 373, 413 and $453 \mathrm{~K}$, respectively, under a feed pressure of 2 bar. The separation of $\mathrm{CO}_{2} / \mathrm{CH}_{4}$ gas mixtures was performed by 
the conventional steady-state permeation method using an apparatus described in a previous publication [16]. The mixture separation used a feed flow rate of $40 \mathrm{~cm}^{3}$ (STP)/min and a helium sweep flow rate of $30 \mathrm{~cm}^{3}(\mathrm{STP}) / \mathrm{min}$. The permeance for gas $i\left(P_{m, i}\right)$, permselectivity (i.e. ideal selectivity) of gas $i$ over $j$ $\left(\alpha_{i / j}^{o}\right)$, and mixture separation factor of $\mathrm{CO}_{2}$ over $\mathrm{CH}_{4}\left(\alpha_{\mathrm{CO} / \mathrm{CH} 4}\right)$ are respectively defined by the flowing expressions,

$$
\begin{aligned}
& P_{m, i}=\frac{Q}{A_{m} \cdot t \cdot \Delta P_{i}} \\
& \alpha_{i / j}^{o}=P_{m, i}^{o} / P_{m, j}^{o} \quad(i \neq j) \\
& \alpha_{\mathrm{CO} 2 / \mathrm{CH} 4}=\left(\frac{P_{m, \mathrm{CO} 2}}{P_{m, \mathrm{CH} 4}}\right)_{\text {mixture }}=\frac{y_{\mathrm{CO} 2} / y_{\mathrm{CH} 4}}{x_{\mathrm{CO} 2} / x_{\mathrm{CH} 4}}
\end{aligned}
$$

where $Q(\mathrm{~mol})$ is the moles of component $i$ permeated through the membrane over a time period of $t(\mathrm{~s})$; $\Delta P_{i}$ is the partial pressure difference (i.e., $\Delta P_{i}=P_{i, f}-P_{i, p}$, where $P_{i, f}$ and $P_{i, p}$ are the partial pressures of gas component $i$ in the feed and permeate sides, respectively); $P_{m, i}^{o}$ and $P_{m, j}^{o}$ are permeance given by equation (1) for pure gas feed; and $x$ and $y$ are molar fractions of the feed and permeate gas, respectively.

\section{Results and discussion}

\subsection{Membrane characterization}

The as-synthesized Sigma- 1 crystals were of circular disc shape (3-8 $8 \mathrm{~m}$ in diameter and $1-3$ $\mu \mathrm{m}$ of thickness) as shown in Fig. 1, which are very similar to those in our previous reports [20,21]. The large Sigma-1 crystals were ball-milled into smaller particles of $0.1-0.3 \mu \mathrm{m}$ in size for coating the seed layer. EDS measurements for both the as-synthesized and ball-milled Sigma-1 crystals showed Si/Al atomic ratio of $51.2 \pm 14$ in the structure. Fig. 2 shows the XRD patterns of the Sigma- 1 particles before ball-milling, the $\alpha$-alumina disc, the ball-milled Sigma-1 particle coated alumina disc, and the DDR-type zeolite membrane obtained by hydrothermal treatment of the Sigma-1 seeded substrate. The results of 
XRD examinations confirmed that Sigma-1 particles and the DDR membrane layer had no appreciable XRD peaks of any impurity crystal phases.

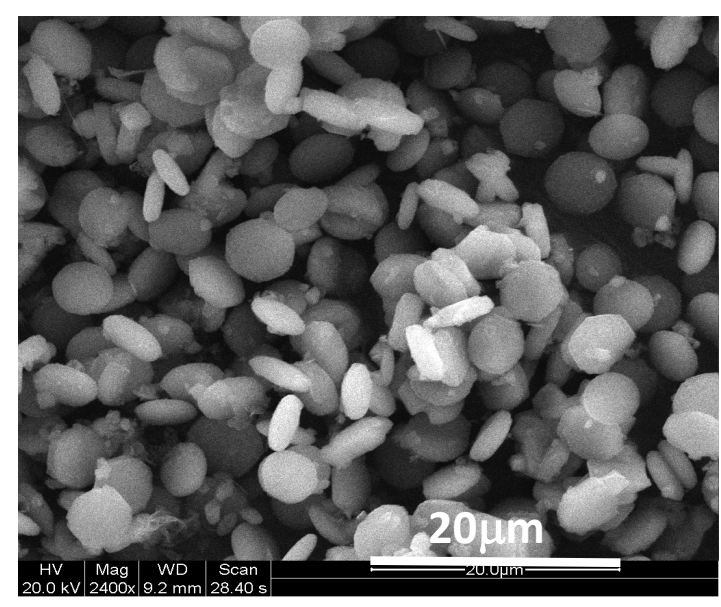

Fig. 1. SEM picture of the as-synthesized Sigma-1 zeolite crystals.

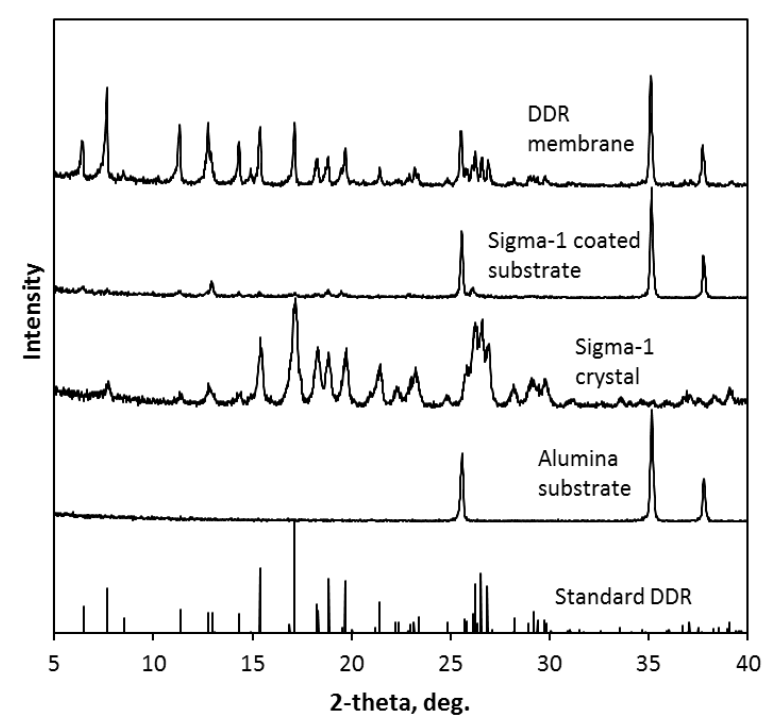

Fig. 2. XRD patterns of the alumina substrate, as-synthesized Sigma-1 particles, ball-milled Sigma-1 zeolite coated substrate, the DDR membrane, and the DDR powder standard [23].

Based on the cross-sectional SEM image in Fig. 3 (b), the ball-milled Sigma-1 layer had a thickness of around $5 \mu \mathrm{m}$. After the secondary hydrothermal crystallization in the aluminum-free precursor, an apparently dense layer of DDR type zeolite was formed and the effective thickness of the dense layer was around $10 \mu \mathrm{m}$ including the original region of Sigma-1 seed layer (Fig. 3-d). The Sigma- 
1 seed layer was obviously also densified according to the contrast between the microscopic textures before and after the secondary growth shown in Fig. 3 (b) and (d), respectively.

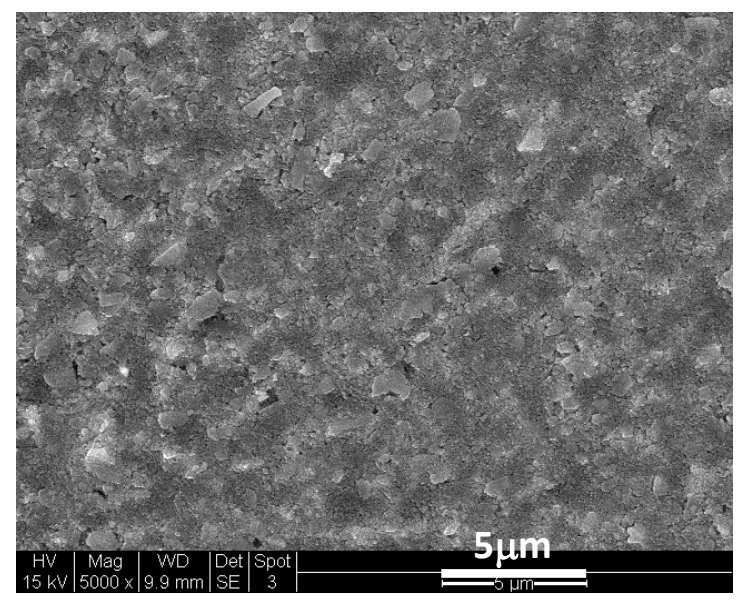

(a)

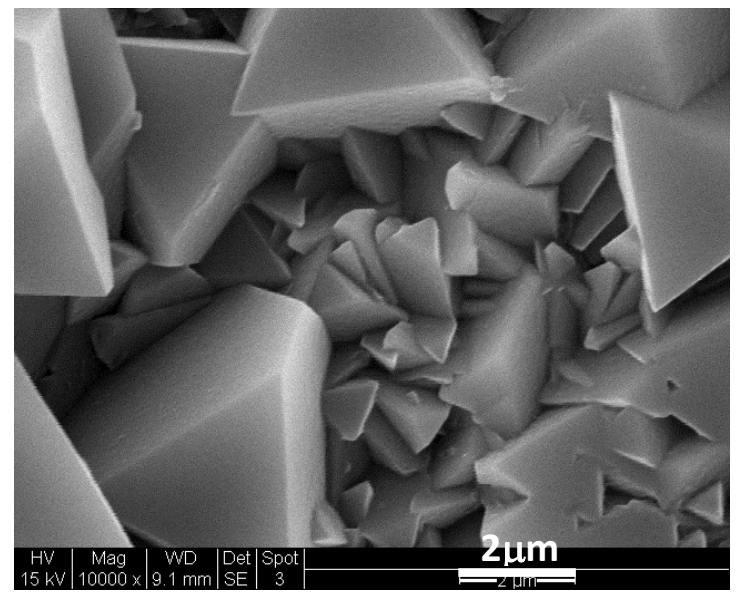

(c)

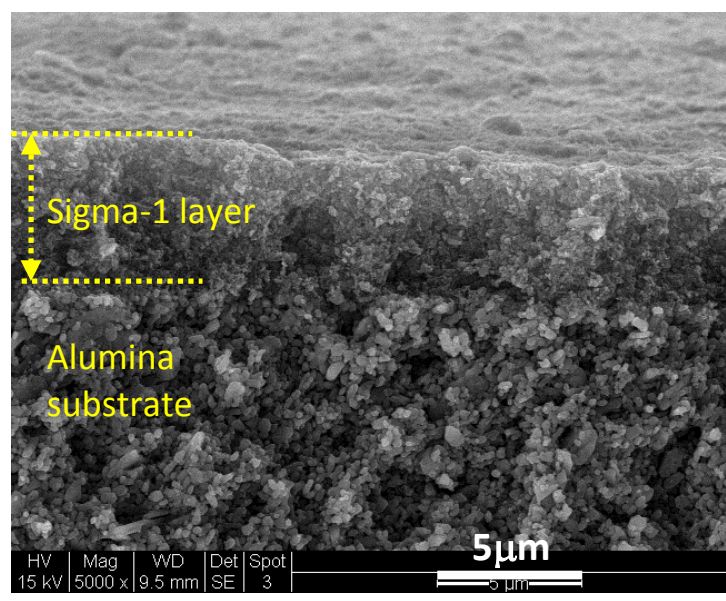

(b)

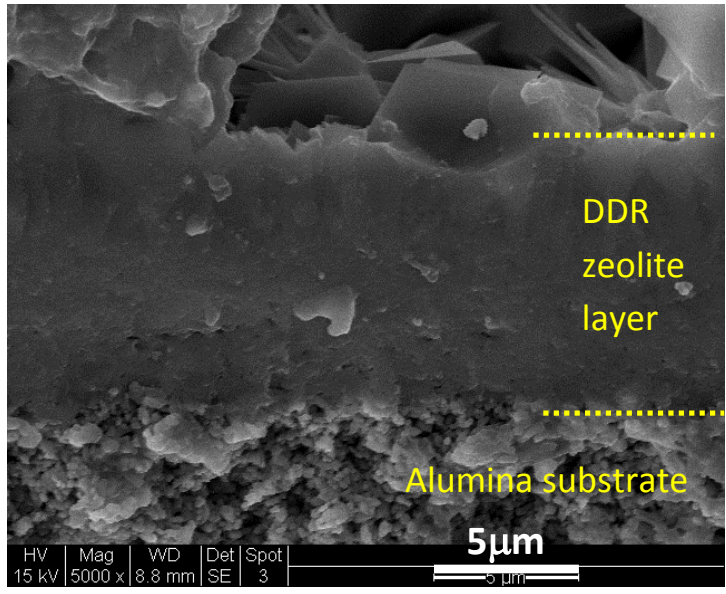

(d)

Fig. 3. SEM images of the Sigma-1 seed layer coated on the alumina substrate ( $a$ - surface; $b$ - crosssection) and the DDR zeolite membrane obtained after hydrothermal secondary growth (c - surface; and d - cross-section).

The EDS analysis was performed at the zeolite membrane outer surface and four different locations along the membrane thickness as shown in Fig. 4. The Si/Al ratios of the five locations are provided in Table 1 . The $\mathrm{Si} / \mathrm{Al}$ atomic ratio of each location was a mean value of five measurements 
taken at separate spots in similar distances to the zeolite/alumina substrate interface. The Si/Al ratio was $\sim 234$ at the zeolite surface (measured with insident beam pependticular to the surface) and was 122 at location “Area 1", which is right beneath the surface as indicated in Fig. 4. The Si/Al ratio in "Area 2" was $\sim 56$, which was close to that of the Sigma-1 seed ( $\mathrm{Si} / \mathrm{Al}$ ratio $\sim 51$ ), because the survey area was about $4-6 \mu \mathrm{m}$ away from the zeolite/substrate interface covering part of the Sigma-1 seed layer. The Si/Al ratio in "Area 3" near the zeolite/substrate interface was $~ 19.5$, likely because of the partial inclusion of some alumina substarte surface. The minimal aluminum content in the outer surface of the zeolite layer could be partially from the incorporated crystallization of the aluminate ions dissolved from the Sigma-1 seeds and/or substrate surface by the highly alkaline precursor solution during hydrothermal treatment. However, the $\mathrm{Na} / \mathrm{Al}$ atomic ratio at the the outer surface of the membrane was 0 , which suggests that the $\mathrm{Si} / \mathrm{Al}$ ratio in the outmost DDR layer must be much higher than 234 . A Na/Al ratio of $~ 1.0$ is expected for framework $\mathrm{Al}^{3+}$ ions because of the required electrical balance between the charge compennsator $\mathrm{Na}^{+}$ and tetrahedron $\mathrm{AlO}_{2}^{-}$sites. The very small $\mathrm{Al}$-content detected at surface might be largely from contaminants but not in the zeolite framework or influences from the Sigma-1 layer deeper in the film and the alumina substrate. This is also supported by the fact that the $\mathrm{Na} / \mathrm{Al}$ ratio increased from the outer surface to the zeolite/substrate interface but was always much less than 1.0. The "Area 4" was inside the substrate near zeolite/substrate interface and the very small $\mathrm{Si} / \mathrm{Al}$ ratio $(\sim 0.054)$ suggests that no signficant deposition of silicates or formation of zeolitic materials have occurred inside the pores of the alumina support. The very minimal Na detected in the alumina support can be attributed to the surface deposition of sodium silicates during the hydrothermal treatment. 


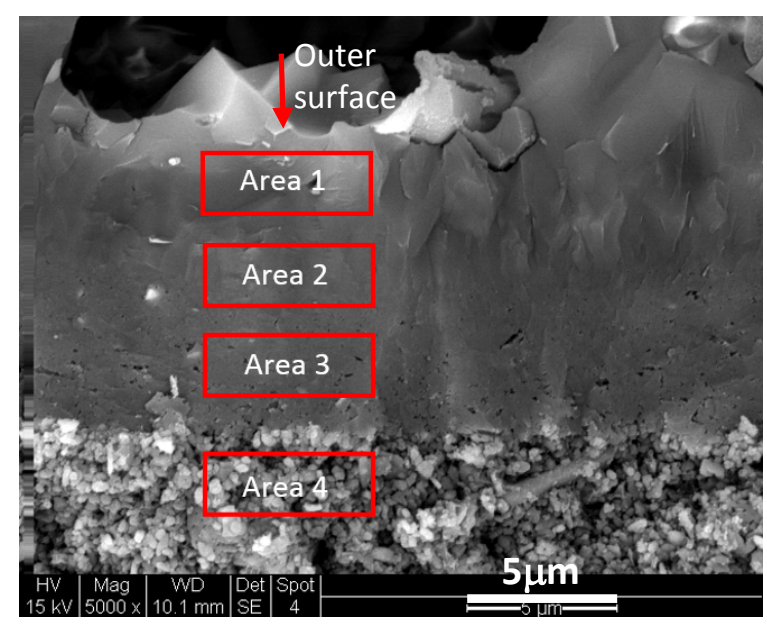

Fig. 4. SEM picture indicating the locations selected for EDS analysis along the membrane thickness.

Table 1. Si/Al and $\mathrm{Na} / \mathrm{Al}$ atomic ratios measured by EDS analysis at locations indicated in Fig. 4

\begin{tabular}{lcccccc}
\hline Location & Zeolite & Area 1 & Area 2 & Area 3 & Area 4 & Sigma-1 \\
& surface & & & & & seed \\
& & & & & & \\
\hline Si/Al ratio & $234 \pm 69$ & $122 \pm 12$ & $55.6 \pm 6$ & $19.5 \pm 0.8$ & $0.054 \pm 0.002$ & $51.2 \pm 14$ \\
$\mathrm{Na} /$ Al ratio & $\sim 0.00$ & $0.15 \pm 0.11$ & $0.31 \pm 0.09$ & $0.38 \pm 0.03$ & $\sim 4.2 \times 10^{-4}$ & $1.2 \pm 0.31$ \\
& & & & & & \\
\hline
\end{tabular}

3.2. Membrane modification and single gas permeation

The single gas permeation was performed at $297 \mathrm{~K}$ for the alumina substrate and the activated DDR membrane before and after the defect repairing modification by liquid phase chemical deposition. Before modification, pure gas permeance through the DDR membrane decreased with increasing molecular weight in the order of $\mathrm{H}_{2}>\mathrm{He}>\mathrm{CH}_{4}>\mathrm{N}_{2}>\mathrm{O}_{2}>\mathrm{CO}_{2}>i-\mathrm{C}_{4} \mathrm{H}_{10}$, which is the same as that observed on the bare alumina substrate. Moreover, the permeance of each gas on the unmodified DDR membrane remained very high, which was approximately half that of the bare substrate as can be seen in Fig. 5 (a). The permselectivities between the gases, for example the $\alpha_{H 2 / i}^{o}$ presented Fig. 5 (b), were close to the theoretical values predicted by the Knudsen diffusion mechanism, i.e. "Knudsen factor" 
$\alpha_{H 2 / i, K}^{o}=\sqrt{M_{w, i} / M_{w, H 2}}$ where $M_{w, i}$ is the molecular weight of gas $i$. These suggest that large amounts of big size defects have formed in the DDR zeolite layer during the high temperature firing process since the membrane was confirmed to be free of pinholes and virtually impermeable to helium before calcination.

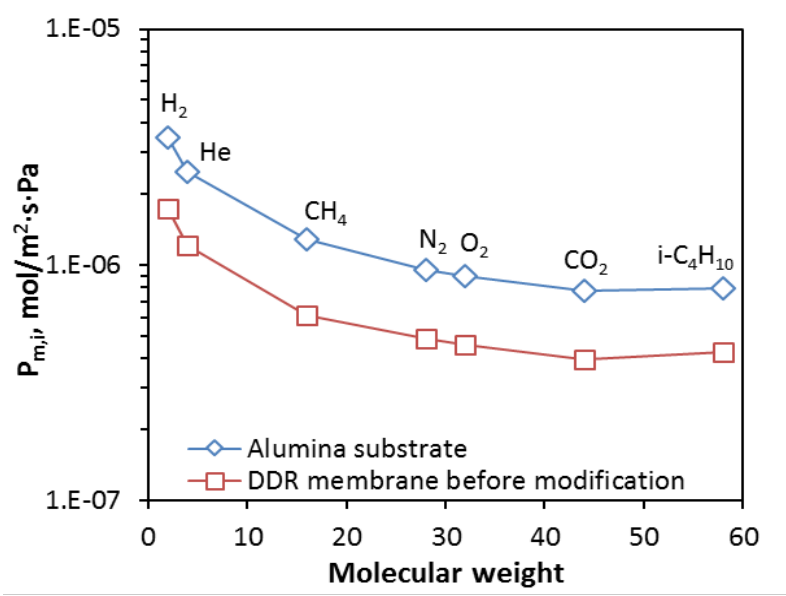

(a)

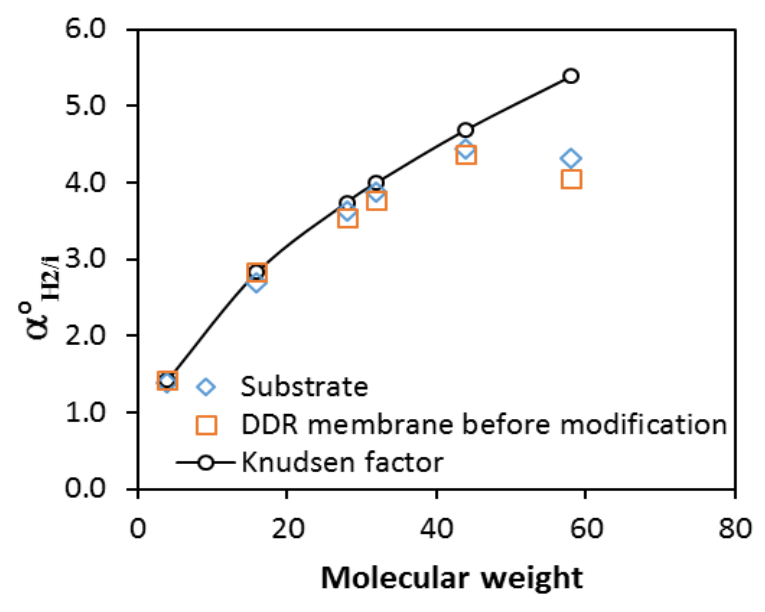

(b)

Fig. 5. Results of single gas permeation for the alumina substrate and the activated DDR membrane prior to modification: (a) permeance as a function of gas molecular weight, and (b) $\mathrm{H}_{2}$-permselectivity ( $\alpha_{H 2 / i}^{o}$ ) as a function of gas $i$ molecular weight. 
The SEM examinations, as shown in Fig. 6, revealed long crack lines in the zeolite membrane surface and evidences of crack penetrating through the entire zeolite film thickness. The width of the cracks ranged from $50 \mathrm{~nm}$ to $200 \mathrm{~nm}$ that explains the predominant Knudsen diffusion gas transport behavior. Kim et al. [10] observed very similar cracks formed in $\alpha$-alumina supported pure-silica DDR membranes, which likely caused the membrane's poor gas permselectivity. In the current membrane, the inclusion of the Sigma-1 seeds in the zeolite layer might also have played a role in crack development during the thermal treatment that needs to be further investigated in the future. Due to the very small intracrystalline pore size $(0.36 \times 0.44 \mathrm{~nm})$ and relatively large thickness of the DDR zeolite membrane, permeance values of the critically sized molecules through the zeolitic pores are expected to be low due to high mass transport resistances. In this case, gas permeation through a small number of large cracks could become the dominating factor in determining the total gas flux and overall permselectivity [12].

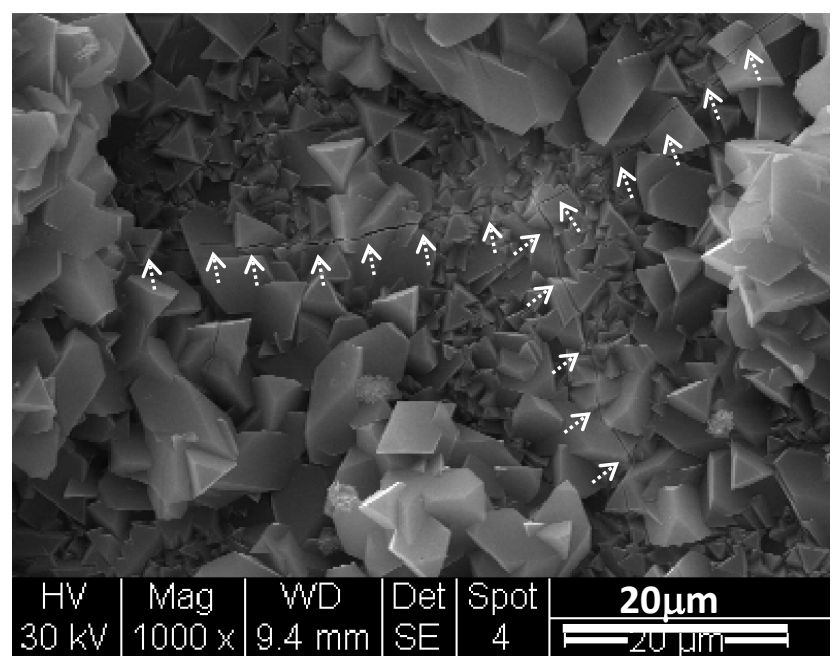

(a)

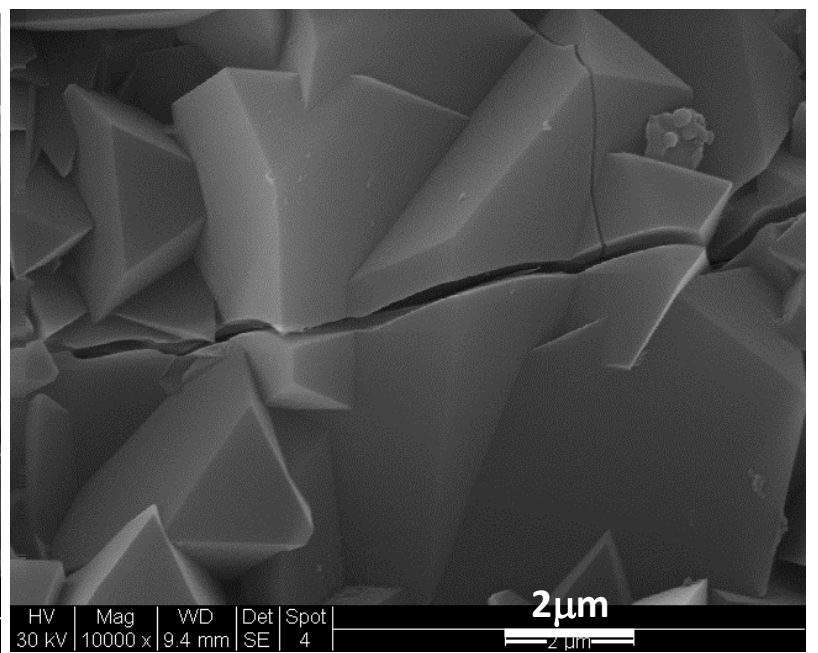

(b) 


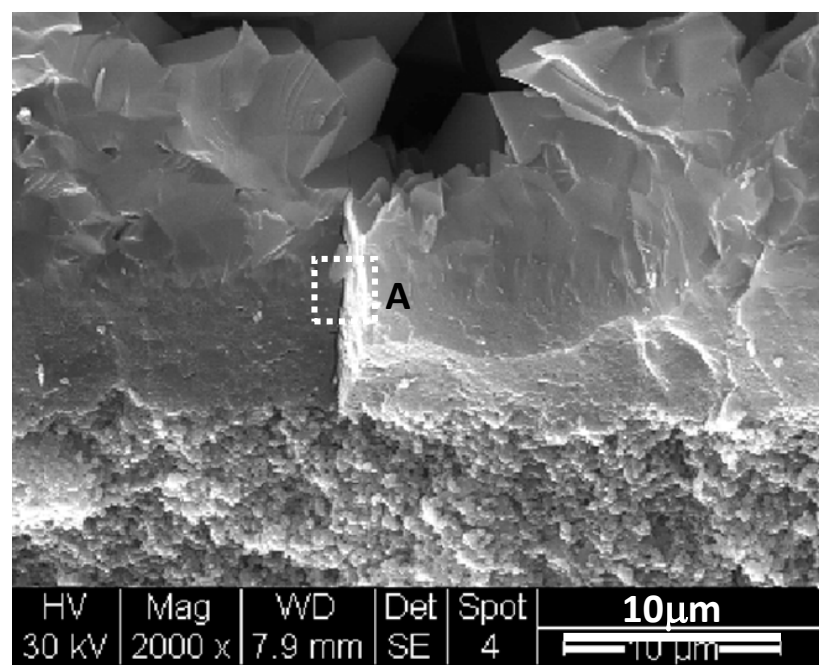

(c)

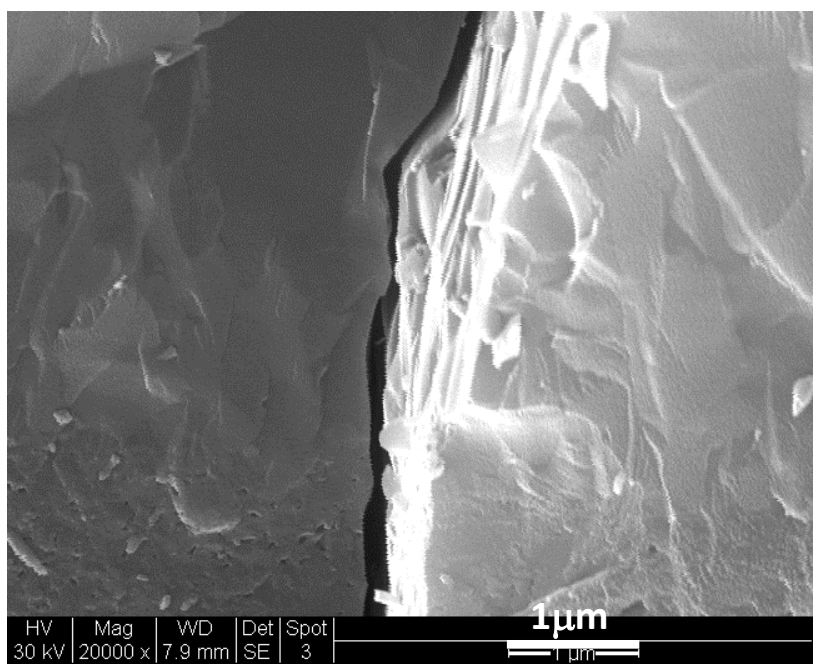

(d)

Fig. 6. SEM pictures of the calcined DDR membrane showing cracks in the surface (a - low magnification; b - high-magnification showing crack widths) and acoss the thickness (c - lownagnification showing crack propagating through the entire thickness; $\mathrm{d}$ - high-magnification showing crack width along the thickness).

The pure gas permeance on the modified membrane is presented as a function of the molecular kinetic diameter $\left(d_{k}\right)$ in Fig. 7 with the data in Fig. 5 included for comparison. The dependence of gas permeance on the molecular size for the modified membrane is in agreement with that reported by Tomita and coworkers [1]. After modification, $P_{m, H 2}^{o}$ of the DDR membrane decreased from $17.3 \times 10^{-7}$ $\mathrm{mol} / \mathrm{m}^{2} \cdot \mathrm{s} \cdot \mathrm{Pa}$ to $1.36 \times 10^{-7} \mathrm{~mol} / \mathrm{m}^{2} \cdot \mathrm{s} \cdot \mathrm{Pa}$ while $P_{m, i C 4}^{o}$ reduced much more drastically from $4.27 \times 10^{-7}$ $\mathrm{mol} / \mathrm{m}^{2} \cdot \mathrm{s} \cdot \mathrm{Pa}$ to $0.00231 \times 10^{-7} \mathrm{~mol} / \mathrm{m}^{2} \cdot \mathrm{s} \cdot \mathrm{Pa}$. The $P_{m, i C 4}^{o}$ of the modified membrane was close to the level of the He permeance before membrane activation because $i-\mathrm{C}_{4} \mathrm{H}_{10}$ has a $d_{k}(\sim 0.50 \mathrm{~nm})$ bigger than the DDR pore opening and is thus excluded by the zeolitic pores [1,7]; on the other hand, $\mathrm{H}_{2}$ has a $d_{k}(0.289 \mathrm{~nm})$ significantly smaller than the DDR pore size and hence has high permeability in the zeolitic pores. These results indicate that the liquid phase chemical deposition technique was able to eliminate or significantly minimize the cracks and intercrystalline spaces in the zeolite layer. 


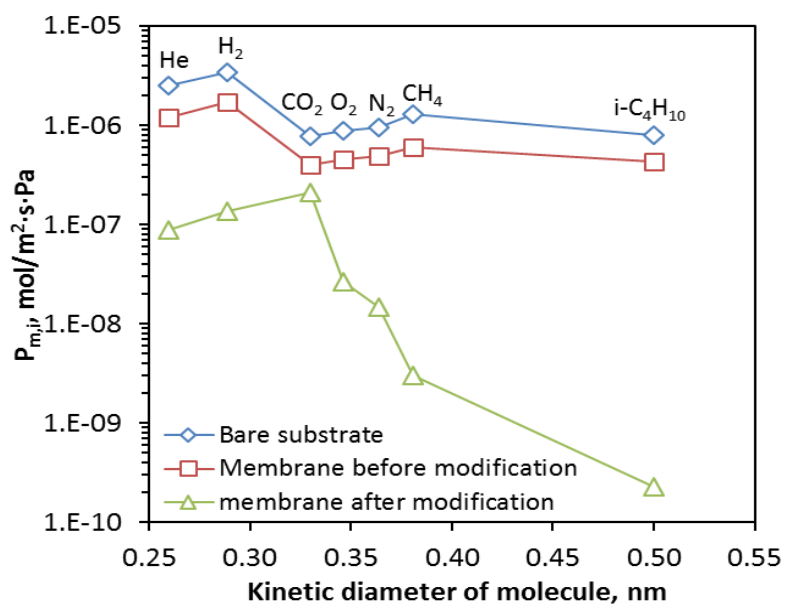

Fig. 7. Gas permeance as a function of molecular kinetic diameter for the DDR membrane before and after modification together with the permeance of the bare substrate.

The SEM examination on the post-modification DDR membranes, as shown in Fig. 8, has revealed silica deposition deep inside the cracks. After the modification, crack lines could still be seen in the surface with deposits visible in some segments of the crack lines in Fig. 8 (a) and (b). However, open spaces of cracks, like those shown in Fig. 6 (c) and (b), were no longer seen by carefully scanning over a large range of the membrane's fractured cross-section. There were a few places where the fracture patterns looked very similar to the locations of cracks in Fig. 6 (c) but appeared to be covered with solid deposits over the entire zeolite film thickness in Fig. 8 (c). The deposits are clearly shown by their distinct nanosphere-looking surface texture in Fig. 8 (d) in contrast to the sharp and smooth surface of the fractured zeolite crystals on its left side and at its corresponding location in Fig. 6 (d). 


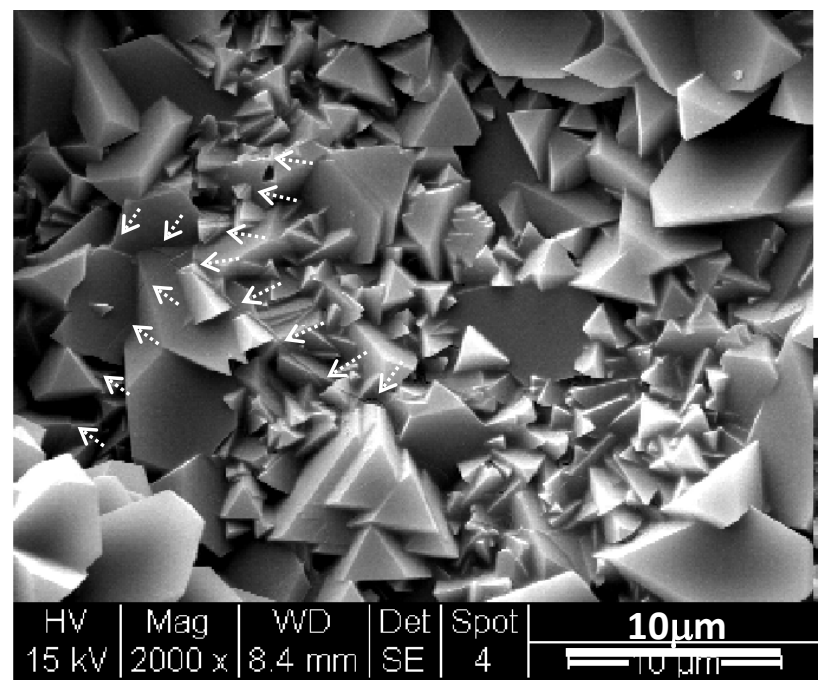

(a)

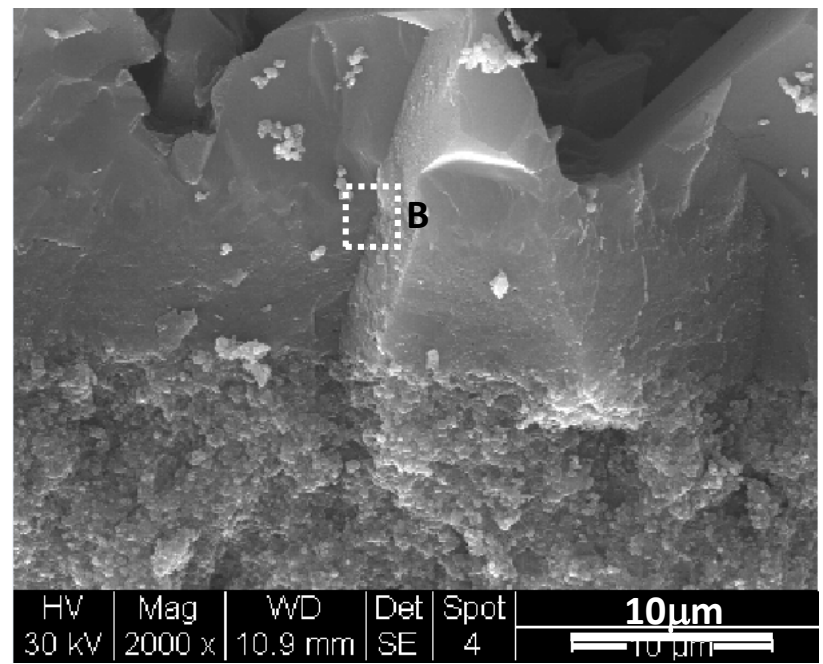

(c)

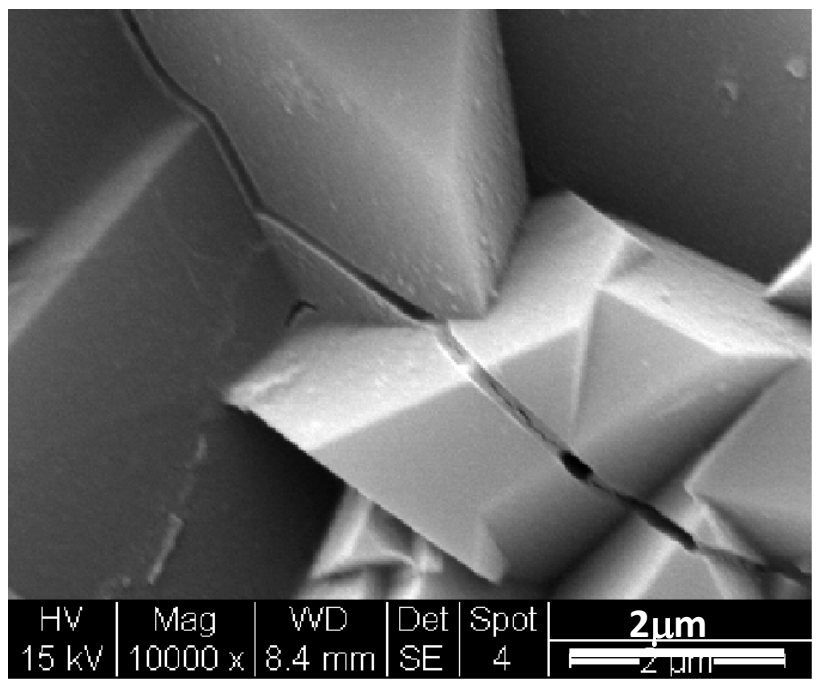

(b)

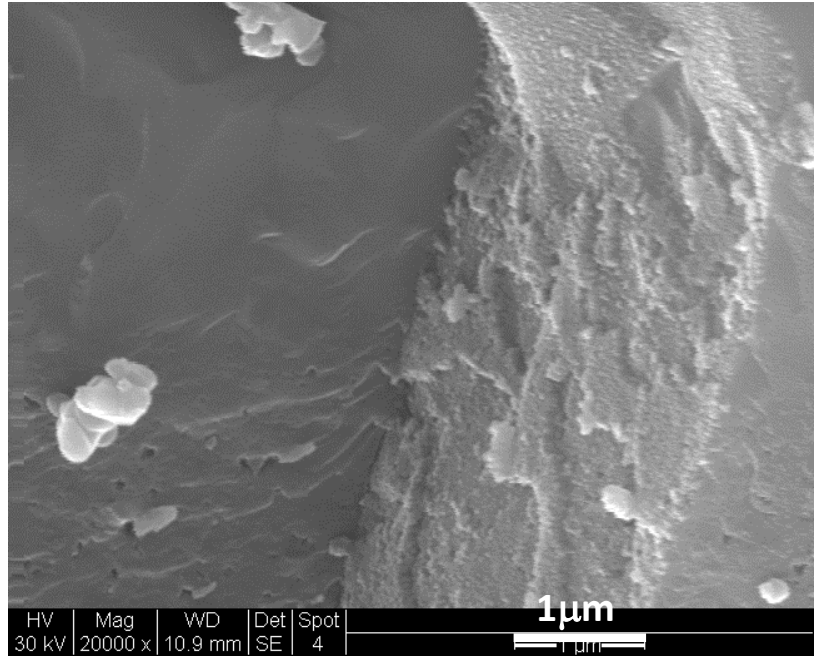

(d)

Fig. 8. SEM pictures of the fractured cross-section of a modified DDR membrane: (a) repaired crack lines in surface, (b) an enlarged view of a repaired crack in suface, (c) a repaired crack along thickness, and (d) enlarged view of the sideface in a repaired crack.

The successful elimination of cracks and minimization of nonselective defects in the zeolite membrane are also proven by the changes in permselectivity between the gases presented in Fig. 7. The permselectivity $\alpha_{O 2 / N 2}^{o}$ changed from 0.939 (i.e. $\mathrm{N}_{2}$-selective) before modification to 1.8 (i.e. $\mathrm{O}_{2}$-selective) 
after modification, which is very close to the value reported by van den Bergh et al. [3] on a DDR membrane from the NGK group (Japan). Since both gases are weakly adsorbing in the DDR zeolite with similar amount of adsorption, such an $\alpha_{O 2 / N 2}^{o}(\sim 1.8)$ indicates that transport of these gases in the modified membrane was primarily through the zeolitic pores and governed by the size-selective activated diffusion mechanism because the kinetic sizes of $\mathrm{O}_{2}\left(d_{k} \sim 0.346 \mathrm{~nm}\right)$ and $\mathrm{N}_{2}\left(d_{k} \sim 0.364 \mathrm{~nm}\right)$ are very close to the zeolite pore diameter $\left(d_{p}\right)[24,25]$. It has been well-documented in the literature that a He-permselectivity over $\mathrm{H}_{2}$ could be achieved in pore size of $0.30 \sim 0.33 \mathrm{~nm}[25,26]$. The modified DDR membrane remained perm-selective towards the lighter but bigger $\mathrm{H}_{2}\left(d_{k} \sim 0.289 \mathrm{~nm}\right)$ over the heavier but smaller He $\left(d_{k} \sim 0.26 \mathrm{~nm}\right)$ possibly because their kinetic sizes are still small enough to achieve gaseous diffusion in the DDR zeolite pores. However, Kanezashi et al. [4] reported $\alpha_{\mathrm{He} / \mathrm{H} 2}^{o}>1$ on a DDR membrane from NGK (Japan) after more than $40 \mathrm{~h}$ of CVD modification. The mechanism of $\mathrm{H}_{2}$ and He diffusion in the DDR zeolite may deserve further investigation because CVD modification could cause mono silica deposition to reduce the zeolitic pore opening. The permselectivity between the heavier but smaller-sized $\mathrm{CO}_{2}\left(d_{k} \sim 0.33 \mathrm{~nm}\right)$ and the lighter but bigger $\mathrm{CH}_{4}\left(d_{k} \sim 0.381 \mathrm{~nm}\right)$ was also reversed from being $\mathrm{CH}_{4}{ }^{-}$ permselective ( $\alpha_{\mathrm{CO} / \mathrm{CH} 4}^{o} \sim 0.65$ ) pre-modification to $\mathrm{CO}_{2}$-permselective ( $\alpha_{\mathrm{CO} / \mathrm{CH} 4}^{o} \sim 69.4$ ) post-modification. However, the high permselectivity between these two strongly adsorbing gases in the modified membrane was caused not just by the difference in the molecular size-dependent diffusivity but also, very importantly, by the much greater adsorption amount of $\mathrm{CO}_{2}$ in the DDR pores $[3,6,7,27]$.

The permselectivity values of the three pairs of molecules, including $\alpha_{\mathrm{H} 2 / \mathrm{He}}^{o}, \alpha_{\mathrm{O} 2 / \mathrm{N} 2}^{o}$, and $\alpha_{\mathrm{CO} 2 / \mathrm{CH} 4}^{o}$, and the near impermeability for $i-\mathrm{C}_{4} \mathrm{H}_{10}\left(d_{k} \sim 0.50 \mathrm{~nm}\right)$, are expected for pore diameter around $0.4 \mathrm{~nm}$. Because the TMOS molecule $\left(\left[\mathrm{CH}_{3} \mathrm{O}\right]_{4} \mathrm{Si}\right)$ is far too large to enter the DDR pore opening, deposition of silica modifiers inside the zeolitic pores cannot occur. Some deposition of particulate silica modifier on the zeolite external surface could be seen in Fig. 8 (b) because of minimal water diffusion to the TMOS side of the membrane surface for hydrolysis reactions. However, such external surface deposition, which might cause minimal partial blockage of the zeolite pore openings, did not seem to significantly affect the 
membrane permeability. The modified DDR membrane of this work exhibited higher $P_{m, \mathrm{CO} 2}\left(2.1 \times 10^{-7}\right.$ $\left.\mathrm{mol} / \mathrm{m}^{2} \cdot \mathrm{s} \cdot \mathrm{Pa}\right)$ but slightly lower $\alpha_{\mathrm{CO} / \mathrm{CH} 4}^{o}(\sim 69)$ than those reported by Tomita and Himeno and coworkers on DDR membranes with similar thicknesses $\left(P_{m, \mathrm{CO} 2} \sim 0.7-1.3 \times 10^{-7} \mathrm{~mol} / \mathrm{m}^{2} \cdot \mathrm{s} \cdot \mathrm{Pa}\right.$ and $\alpha_{\mathrm{CO} 2 / \mathrm{CH} 4}^{o} \sim 68-$ 280) [1,2]. These may be caused by the microporous structure of the silica modifier filled in the cracks of the current membrane while the reference membrane had almost negligible pathways of greater than 0.5 $\mathrm{nm}$ as indicated by its extremely low $\mathrm{i}-\mathrm{C}_{4} \mathrm{H}_{4}$ permeance. The gas transport properties of the membrane could be also influenced by the difference of aluminum content in the zeolite framework, which was apparently higher in the current zeolite membrane than in the nearly pure-silica membranes reported in the reference [1].

The effect of DDR membrane modification was quite reproducible with reasonable variations between individual membranes as shown by the examples given in Table 2, where three membranes synthesized under identical conditions exhibited similar changes in $P_{m, \mathrm{CH} 4}^{o}$ and $P_{m, \mathrm{CO} 2}^{o}$ and generally consistent improvements in $\alpha_{\mathrm{CO} / \mathrm{CH} 4}^{o}$ after modification. The gas permeation data presented hereafter in this paper were measured on "Membrane 1" in Table 2.

Table 2. Results of $\mathrm{CO}_{2}$ and $\mathrm{CH}_{4}$ single gas permeation at $297 \mathrm{~K}$ and feed pressure of 2 bar for three identically made DDR membranes before and after modification

\begin{tabular}{|c|c|c|c|c|c|c|c|}
\hline \multirow{2}{*}{ Membrane } & \multirow{2}{*}{ Substrate } & \multicolumn{2}{|c|}{ Membrane 1} & \multicolumn{2}{|c|}{ Membrane 2} & \multicolumn{2}{|c|}{ Membrane 3} \\
\hline & & Before & After & Before & After & Before & After \\
\hline$P_{m, \mathrm{CO} 2}^{o}, 10^{-7} \mathrm{~mol} / \mathrm{m}^{2} \cdot \mathrm{s} \cdot \mathrm{Pa}$ & 12.6 & 3.96 & 2.10 & 4.23 & 1.12 & 4.07 & 1.66 \\
\hline$P_{m, C H 4}^{o}, 10^{-7} \mathrm{~mol} / \mathrm{m}^{2} \cdot \mathrm{s} \cdot \mathrm{Pa}$ & 7.79 & 6.09 & 0.0303 & 6.35 & 0.0217 & 5.98 & 0.0395 \\
\hline$\alpha_{\mathrm{CO} 2 / \mathrm{CH} 4}^{o}$ & 0.606 & 0.650 & 69.3 & 0.666 & 51.6 & 0.681 & 42.0 \\
\hline
\end{tabular}

\section{3. $\mathrm{CO}_{2} / \mathrm{CH}_{4}$ mixture separation}


The results of $\mathrm{CO}_{2} / \mathrm{CH}_{4}$ mixture separation by the modified DDR membrane obtained at $297 \mathrm{~K}$ and 2 bar feed pressure are presented in Fig. 9. The $\mathrm{CO}_{2}$ permeance obtained from $\mathrm{CO}_{2} / \mathrm{CH}_{4}$ mixture permeation remained nearly constant at $P_{m, \mathrm{CO} 2} \sim 1.8 \times 10^{-7} \mathrm{~mol} / \mathrm{m}^{2} \cdot \mathrm{s} \cdot \mathrm{Pa}$ regardless of the $\mathrm{CO}_{2}$ molar fraction in the feed, which was only slightly smaller than the value measured from pure $\mathrm{CO}_{2}$ feed ( $P_{m, \mathrm{CO} 2}^{o} \sim 2.1 \times 10^{-7} \mathrm{~mol} / \mathrm{m}^{2} \cdot \mathrm{s} \cdot \mathrm{Pa}$ ). The very small difference of $\mathrm{CO}_{2}$ permeance between single gas and $\mathrm{CO}_{2} / \mathrm{CH}_{4}$ mixture permeation in DDR membranes was also reported in the literature [2] although $\mathrm{CH}_{4}$ has a diffusivity far smaller than $\mathrm{CO}_{2}$ in DDR pores $[3,6,7]$ and would be expected to slow down the fast moving $\mathrm{CO}_{2}$ in the zeolitic pores. The fundamental cause of the unusual transport phenomenon of $\mathrm{CO}_{2} / \mathrm{CH}_{4}$ in the DDR zeolite has been elaborated by Lee and Sholl through computational methods [6]. They demonstrated that the transport diffusion of $\mathrm{CO}_{2}$ is only slightly hindered by the presence of $\mathrm{CH}_{4}$ because the adsorbed $\mathrm{CO}_{2}$ molecules preferentially position in the 8-member ring windows between the zeolite cages through which the much larger $\mathrm{CH}_{4}$ only transition from cage to cage. The permeance of $\mathrm{CH}_{4}\left(P_{m, \mathrm{CH} 2}\right)$ however exhibited a more pronounced change, i.e. increasing slightly with its concentration, causing the separation factor $\alpha_{\mathrm{CO} / \mathrm{CH} 2}$ to decrease when the $\mathrm{CH}_{4}$ molecule fraction or partial pressure increased. This is also consistent with the computational findings on the enhancement of $\mathrm{CH}_{4}$ diffusivity at higher molecular loading or gas pressure [6,7]. As a result, the $\alpha_{\mathrm{CO} / \mathrm{CH} 2}$ decreased from $\sim 92$ with $P_{m, \mathrm{CO} 2}$ of $\sim 1.8 \times 10^{-7} \mathrm{~mol} / \mathrm{m}^{2} \cdot \mathrm{s} \cdot \mathrm{Pa}$ for the feed containing $90 \% \mathrm{CO}_{2}$ to 62 with $P_{m, \mathrm{CO} 2}$ of $\sim 1.7 \times 10^{-7}$ $\mathrm{mol} / \mathrm{m}^{2} \cdot \mathrm{s} \cdot \mathrm{Pa}$ for the feed containing $10 \% \mathrm{CO}_{2}$. 


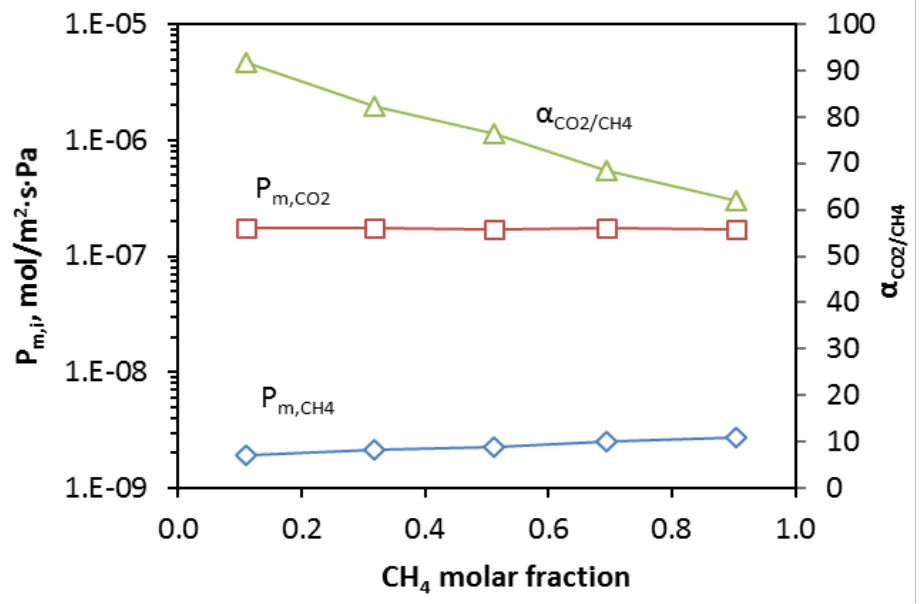

Fig. 9. Performance of the modified DDR membrane for separation of $\mathrm{CO}_{2} / \mathrm{CH}_{4}$ mixtures at $297 \mathrm{~K}$ and 2 bar feed pressure.

The effects of temperature and feed pressure on the modified DDR membrane separation of $\mathrm{CO}_{2} / \mathrm{CH}_{4}$ equimolar mixture were evaluated when the permeate side used ambient pressure helium sweeping flow. Fig. 10 presents the gas permeance and $\mathrm{CO}_{2} / \mathrm{CH}_{4}$ separation factor $\alpha_{\mathrm{CO} 2 / \mathrm{CH} 4}$ as functions of feed pressure and temperature, respectively. The separation factor and individual gas permeance as well as their temperature and pressure dependences of the modified membrane were generally in accordance with the characteristic behaviors of DDR zeolite membrane that have been well documented in the literature $[1-3,6,7]$. The separation of $\mathrm{CO}_{2} / \mathrm{CH}_{4}$ gas mixture through DDR zeolite membranes has been extensively discussed based on the competitive adsorption-diffusion mechanism. The permeability of component $i\left(P_{b, i}\right)$, i.e. $P_{m, i}$ normalized by membrane thickness $(\delta)$, is the product of its solubility and diffusivity in the zeolite, i.e. $P_{b, i}=C_{i} \times D_{i}$, where $C_{i}$ and $D_{i}$ are the solubility (i.e. adsorbate concentration) and diffusivity, respectively. The $\mathrm{CO}_{2} / \mathrm{CH}_{4}$ permeation selectivity is thus given by the ratio of their permeability ( $\left.\alpha_{\mathrm{CO} / \mathrm{CH} 4}=P_{b, \mathrm{CO} 2} / P_{b, \mathrm{CH} 4}\right)$, which is the combination of "adsorption selectivity" $\left(\alpha_{\mathrm{CO} 2 / \mathrm{CH} 4}^{a d s}=C_{\mathrm{CO} 2} / C_{\mathrm{CH} 4}\right)$ and “diffusion selectivity" $\left(\alpha_{\mathrm{CO} 2 / \mathrm{CH} 4}^{\text {diff }}=D_{\mathrm{CO} 2} / D_{\mathrm{CH} 4}\right)$, i.e. $\alpha_{\mathrm{CO} 2 / \mathrm{CH} 4}=\alpha_{\mathrm{CO} 2 / \mathrm{CH} 4}^{a d s} \times \alpha_{\mathrm{CO} 2 / \mathrm{CH} 4}^{\text {diff }}$. 

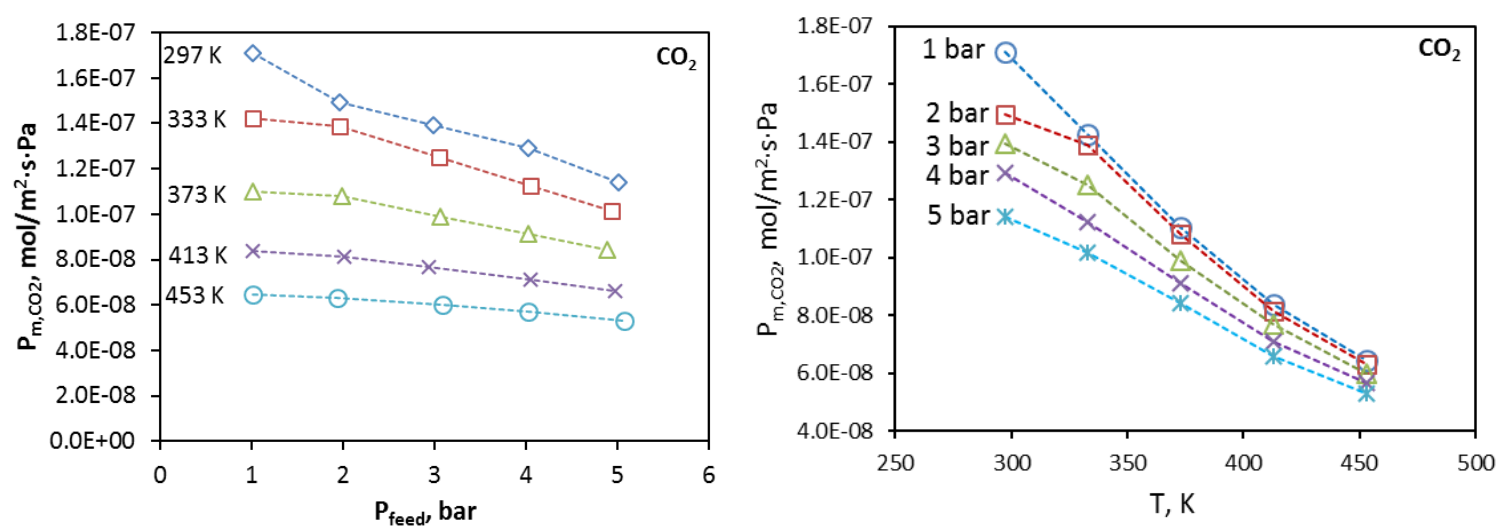

(a)

(b)

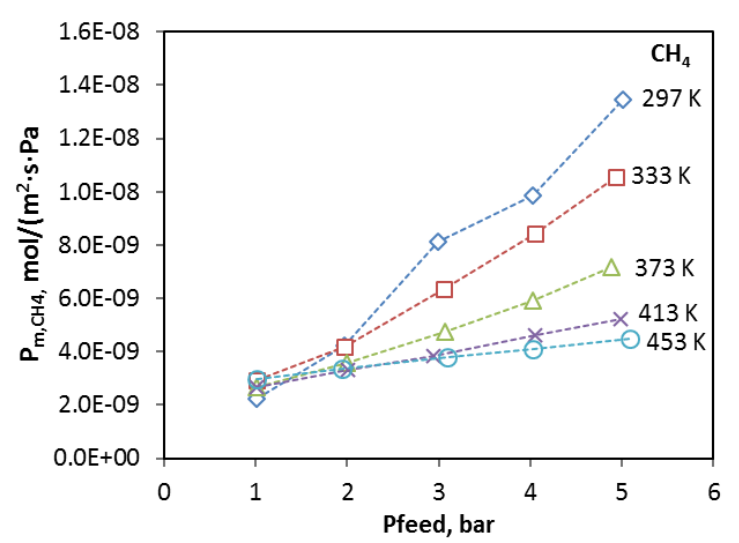

(c)

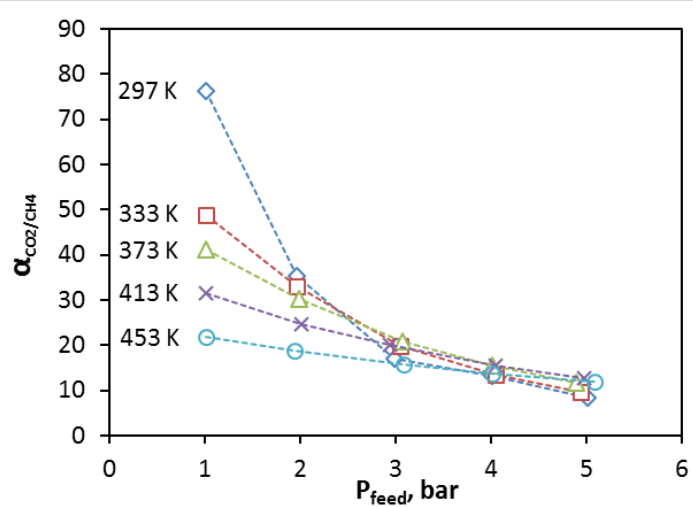

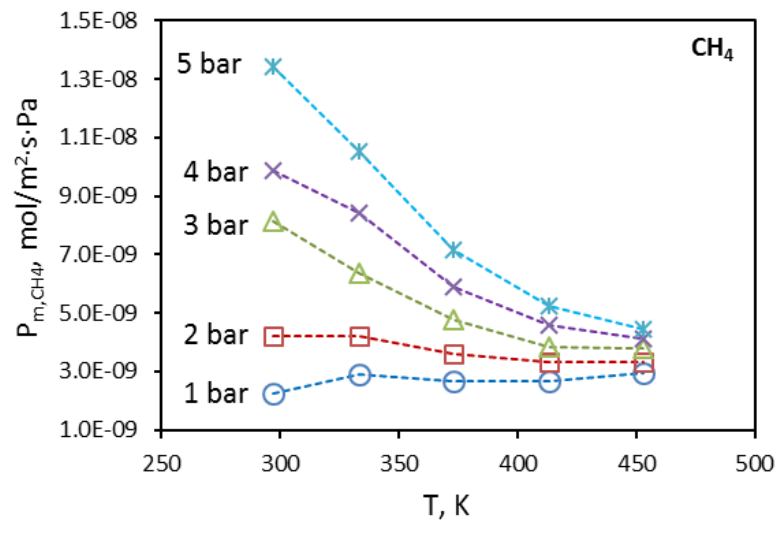

(d)

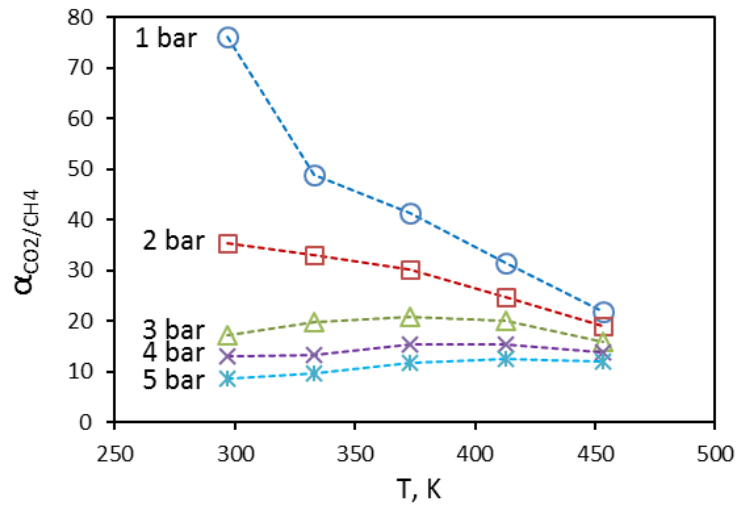

(e)

(f) 
Fig. 10. Effects of feed pressure and operating temperature on separation of $\mathrm{CO}_{2} / \mathrm{CH}_{4}$ equimolar mixture: (a) $P_{m, \mathrm{CO} 2}$ as a function of pressure; (b) $P_{m, \mathrm{CO} 2}$ as a function of temperature; (c) $P_{m, \mathrm{CH} 4}$ as a function of pressure; (d) $P_{m, \mathrm{CH} 4}$ as a function of temperature; (e) $\alpha_{\mathrm{CO} / \mathrm{CH} 4}$ as a function of pressure; (f) $\alpha_{\mathrm{CO} / \mathrm{CH} 4}$ as a function of temperature.

Fig. 10 (a) and (c) show that, at each temperature, when feed pressure increased, $P_{m, \mathrm{CO} 2}$ decreased whereas $P_{m, \mathrm{CH} 4}$ increased, leading to the decline of separation factor $\alpha_{\mathrm{CO} / \mathrm{CH} 4}$. These results agree with the observations on $\mathrm{CO}_{2} / \mathrm{CH}_{4}$ mixture separation by DDR membranes in the literature [1,2]. The diffusivity of $\mathrm{CO}_{2}$ decreases but the diffusivity of $\mathrm{CH}_{4}$ increases with their respective molecular loading (amount of adsorption) in the DDR zeolite that results in decrease of $\alpha_{\mathrm{CO} 2 / \mathrm{CH} 4}^{\text {diff }}$ as gas pressure increases [6]. Although the adsorption selectivity $\alpha_{\mathrm{CO} / \mathrm{CH} 4}^{a d s}$ moderately enhances with increasing pressure, it is much less significant as compared to the decline of $\alpha_{\mathrm{CO} / \mathrm{CH} 4}^{\text {diff }}$ [7]. Thus, increasing feed pressure causes $P_{b, \mathrm{CO} 2}$ to decrease and $P_{b, \mathrm{CH} 4}$ to increase, leading to the decline of $\alpha_{\mathrm{CO} 2 / \mathrm{CH} 4}$ [7]. The pressure-dependence of the gas permeance and separation factor was found to be stronger at lower temperatures because, at high temperature, adsorption of both $\mathrm{CO}_{2}$ and $\mathrm{CH}_{4}$ weakens to reduce $\alpha_{\mathrm{CO2/CH} 4}^{a d s}$ and the decreased $C_{i}$ also reduce the influences on their diffusivity. It is noticed in Fig. 10 (d) that $P_{b, C H}$ increased slightly with temperature at low pressure (1 bar) but decreased with temperature at higher pressures. This may be explained by the fact that, under low pressure, $\mathrm{CH}_{4}$ has a low adsorption loading and the temperaturecaused diffusivity $\left(D_{i}\right)$ enhancement overpowers the loss in adsorption amount $\left(C_{i}\right)$, resulting in an enhanced $P_{m, \text { CH } 4}\left(=P_{b, i} / \delta\right)$. Van den Bergh et al. reported similar temperature-dependence of $\mathrm{CH}_{4}$ single gas permeance in DDR membrane under atmospheric pressure [3]. At higher pressures, the $\mathrm{CH}_{4}$ adsorption (molecular load) becomes increasingly greater and rising temperature can cause larger reduction of $C_{i}$ to overpower the changes of $D_{i}$, leading to decreases in $\mathrm{CH}_{4}$ permeability. The $P_{m, C H 4}$ decreases more rapidly as temperature raises at higher feed pressures. The $\mathrm{CO}_{2}$, which has much higher 
amount of adsorption, had permeance decrease with temperature at all tested pressures but unlike $\mathrm{CH}_{4}$, $P_{b, \mathrm{CO} 2}$ decline with temperature was more rapidly at lower pressure. Thus, the relationship between $\alpha_{\mathrm{CO} 2 / \mathrm{CH} 4}$ and temperature is dependent of feed pressure, namely, when temperature increases, $\alpha_{\mathrm{CO} 2 / \mathrm{CH} 4}$ increases slightly at high pressure but decreases rapidly at low pressures as shown in Fig. 10 (f).

\subsection{Effect of water vapor}

The effect of feed gas humidity on the separation of $\mathrm{CO}_{2} / \mathrm{CH}_{4}$ by the modified DDR membrane was tested by introducing $3 \mathrm{kPa}$ water vapor into the equimolar mixture and the results are shown in Fig. 11. The introduction of the water vapor caused $P_{m, \mathrm{CO} 2}$ to decrease from $1.7 \times 10^{-7} \mathrm{~mol} / \mathrm{m}^{2} \cdot \mathrm{s} \cdot \mathrm{Pa}$ to $5.5 \times 10^{-}$ ${ }^{8} \mathrm{~mol} / \mathrm{m}^{2} \cdot \mathrm{s} \cdot \mathrm{Pa}$ accompanied with a drop of $\alpha_{\mathrm{CO} / \mathrm{CH} 4}$ from $\sim 70$ to 60 after stabilization in about 7 h. The decrease of $\mathrm{CO}_{2}$ permeance in the presence of water vapor was roughly $77 \%$ of the dry gas permeance which was greater than the $50 \sim 60 \%$ reduction on the nearly pure-silica DDR membranes reported by Tomita and coworkers who also reported increases of $\alpha_{\mathrm{CO} / \mathrm{CH} 4}$ upon the introduction of water vapor [1,2]. The relatively larger decrease of gas permeance for humid feed in the current DDR membrane may be attributed to the lower $\mathrm{Si} / \mathrm{Al}$ ratio in the zeolite layer due to the inclusion of Sigma-1 seeds, which made the membrane more hydrophilic causing stronger water adsorption in the zeolitic pores to impose greater hindrance to the gas diffusion. The much stronger water adsorption at zeolite internal surface sites of $\left[\mathrm{AlO}_{2}^{-}\right] \cdot \mathrm{Na}^{+}$was also evidenced by the incomplete recovery of $P_{b, \mathrm{CO} 2}(\sim 73 \%$ recovery $)$ after being dried at $453 \mathrm{~K}$ while the highly siliceous DDR membrane was able to fully recover the $P_{b, \mathrm{CO} 2}$ in dry feed [2]. 


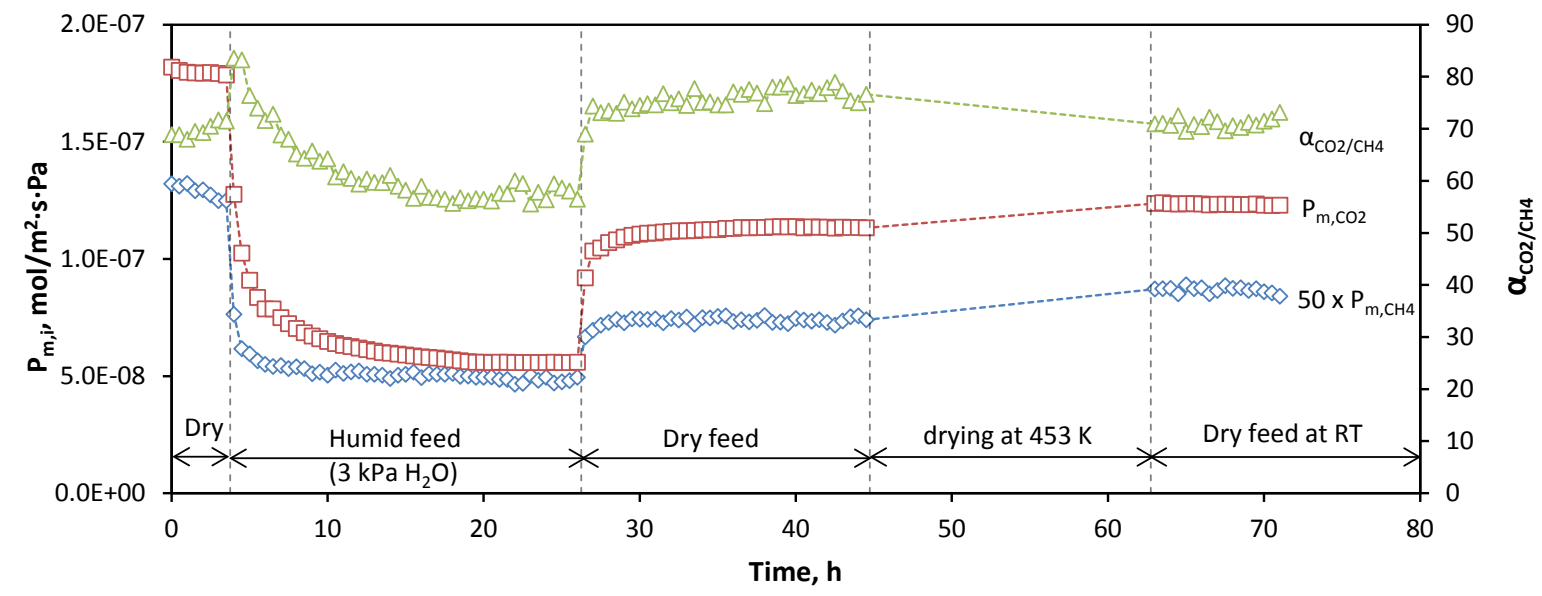

Fig. 11. Separation of equimolar $\mathrm{CO}_{2} / \mathrm{CH}_{4}$ mixtures with and without water vapor in the feed stream at $297 \mathrm{~K}$ and ambient pressure in both feed and permeate sides.

\section{Conclusions}

DDR type zeolite membranes were successfully synthesized by secondary hydrothermal treatment of ball-milled Sigmal-1 zeolite seed layers in an aluminum-free precursor solution containing 1adamantylamine as the structure directing agent. The resultant DDR type membrane had high Si/Al ratio near the outmost zeolite surface and had relatively lower Si/Al ratio in the 5- $\mu$ m thick Al-containing (Si/Al) Sigma-1 seed layer region. The as-synthesized DDR membranes were defect-free but the subsequent removal of SDA at high-temperature induced formation of cracks in the zeolite layer with typical widths ranging from 50 to $200 \mathrm{~nm}$. These cracks undermined the typical gas separation capability expected for a defect-free DDR zeolite membrane. The cracks were effectively eliminated by the liquid phase chemical deposition method using TMOS as precursor. The results of extensive studies on $\mathrm{H}_{2}$, He, $\mathrm{O}_{2}, \mathrm{~N}_{2}, \mathrm{CO}_{2}$, and $\mathrm{CH}_{4}$ pure gas permeation and $\mathrm{CO}_{2} / \mathrm{CH}_{4}$ mixture separation demonstrated that transport of these small molecule gases in the modified membrane was predominantly through the DDR zeolitic pores. At room temperature and 2-bar feed gas pressure, the modified DDR membrane achieved a $\mathrm{CO}_{2} / \mathrm{CH}_{4}$ separation factor of $\sim 92$ for a feed containing $90 \% \mathrm{CO}_{2}$, which decreased to 62 for a feed containing $10 \% \mathrm{CO}_{2}$ while the $\mathrm{CO}_{2}$ permeance stayed nearly independent of the feed composition at $\sim 1.8$ 
$\times 10^{-7} \mathrm{~mol} / \mathrm{m}^{2} \cdot \mathrm{s} \cdot \mathrm{Pa}$. Despite the aluminum content in the zeolite layer, the membrane also showed reasonable tolerance to water vapor in $\mathrm{CO}_{2} / \mathrm{CH}_{4}$ separation and reversibility of separation performance after switching back to dry gas feed. The synthesis approach developed in this study may offer an alternative route to fabricating the DDR type zeolite membranes.

\section{Acknowledgements}

This research was financially supported by the Ohio Air Quality Development Authority/Ohio Coal Development Office (Grant \# OCDO 10-C34-N) and the U.S. Department of Energy/NETL (Grant \# DE-FE0026435).

\section{References}

[1] T. Tomita, K. Nakayama, H. Sakai, Gas separation characteristics of DDR type zeolite membrane. Micropor. Mesopor. Mater. 68 (2004) 71-75.

[2] S. Himeno, T. Tomita, K. Suzuki, K. Nakayama, K. Yajima, S. Yoshida, Synthesis and permeation properties of a DDR-type zeolite membrane for separation of $\mathrm{CO}_{2} / \mathrm{CH}_{4}$ gaseous mixtures. Ind. Eng. Chem. Res. 46 (2007) 6989-6997.

[3] J. van den Bergh, W. Zhu, J. Gascon, J.A. Moulijn, F. Kapteijn, Separation and permeation characteristics of a DD3R zeolite membrane. J. Membr. Sci. 316 (2008) 35-45.

[4] M. Kanezashi, J. O'Brien-Abraham, Y.S. Lin, K. Suzuki, Gas permeation through DDR-type zeolite membranes at high temperatures. AIChE J. 54 (2008) 1478-1486.

[5] Z. Zheng, A.S. Hall, V.V. Guliants, Synthesis, characterization and modification of DDR membranes grown on alpha-alumina supports. J. Mater. Sci. 43 (2008) 2499-2502.

[6] S.E. Jee, D.S. Sholl, Carbon dioxide and methane transport in DDR zeolite: insights from molecular simulations into carbon dioxide separations in small pore zeolites. J. Am. Chem. Soc. 131 (2009) 7896-7904. 
[7] R. Krishna, J.M. van Baten, In silico screening of zeolite membranes for $\mathrm{CO}_{2}$ capture. J. Membr. Sci. 360 (2010) 323-333.

[8] J. van den Bergh,W. Zhu, J.C. Groen, F. Kapteijn, J.A. Moulijn, K. Yajima, K. Nakayama, T. Tomita, S. Yoshida, Natural gas purification with a DDR zeolite membrane; permeation modelling with Maxwell-Stefan equations. Stud. Surf. Sci. Catal. 170A (2007) 1021-1027.

[9] J. van den Bergh, A. Tihaya, F. Kapteijn, High temperature permeation and separation characteristics of an all-silica DDR zeolite membrane. Micropor. Mesopor. Mater. 132 (2010) 137-147.

[10] E. Kim, W. Cai, H. Baik, J. Nam, J. Choi, Synthesis and sonication-induced assembly of Si-DDR particles for close-packed oriented layers. Chem. Comm. 49 (2013) 7418-7420.

[11] A. Bose, M. Sen, J.K. Das, N. Das, Sonication mediated hydrothermal process - an efficient method for the rapid synthesis of DDR zeolite membranes. Rsc Adv. 4 (2014) 19043-19052.

[12] J. Dong, Y.S. Lin, M. Kanezashi, Z. Tang, Microporous inorganic membranes for high temperature hydrogen purification. J. App. Phys. 104 (2008) 121301.

[13] S.H. Park, R.-W. Große Kunstleve, H. Graetsch, H. Gies, The thermal expansion of the zeolites MFI, AFI, DOH, DDR and MTN in their calcined and as synthesized forms. Stud. Surf. Sci. Catal. 105 (1997) 1989-1994.

[14] J.H. Dong, Y.S. Lin, M.Z.C. Hu, R.A. Peascoe, E.A. Payzant, Template-removal-associated microstructural development of porous-ceramic-supported MFI zeolite membranes. Micropor. Mesopor. Mater. 34 (2000) 241-253.

[15] M. Nomura, T. Yamaguchi, S. Nakao, Silicalite membranes modified by counterdiffusion CVD technique. Ind. Eng. Chem. Res. 36 (1997) 4217-4223.

[16] X. Gu, Z. Tang, J. Dong, On-stream modification of MFI zeolite membranes for enhancing hydrogen separation at high temperature. Micropor. Mesopor. Mater. 111 (2008) 441-448.

[17] B. Zhang, C. Wang, L. Lang, R. Cui, X. Liu, Selective defect-patching of zeolite membranes using chemical liquid deposition at organic/aqueous interfaces. Adv. Funct. Mater. 18 (2008) 3434-3443. 
[18] J. Dong, L. Li, T.M. Nenoff, MFI zeolite membranes for reverse osmosis desalination: effect and modification of intercrystalline pores. in "Desalination Research Progress”. D. J. Delgado, P. Moreno Ed., Nova Science Publishers, Inc., New York, 2008, pp 373 - 388.

[19] Z. Hong, C. Zhang, X. Gu, W. Jin, N. Xu, A simple method for healing nonzeolitic pores of MFI membranes by hydrolysis of silanes. J. Membr. Sci. 366 (2011) 427-435.

[20] S. Yang, J. Provenzano, A. Arvanitis, W. Jing, J. Dong, Morphological control of DDR zeolite crystals in Sigma-1 assisted hydrothermal synthesis using reduced organic agents. J. Porous Mater. 21 (2014) 1001-1007.

[21] F. Zheng, W. Jing, X. Gu, N. Xu, J. Dong, Rapid synthesis of pure DD3R zeolite using ball-milled Sigma-1 seeds under static conditions. J. Mater. Sci. 48 (2013) 6286-6292.

[22] J. Dong, Y.S. Lin, In situ synthesis of P-type zeolite membranes on porous alpha-alumina supports. Ind. Eng. Chem. Res. 37 (1998) 2404-2409.

[23] C. Baerlocher , L.B. McCusker, D.H. Olson (Ed.), “Atlas of Zeolite Framework Types (7th Ed.),” Structure Commission of the international Zeolite Association, Elsevier, Oxford, UK.

[24] J.R. Xiao, J. Wei, Diffusion mechanism of hydrocarbons in zeolites: 1. Theory. Chem. Eng. Sci. 47 (1992) 1123-1141.

[25] Z. Tang, J. Dong, T.M. Nenoff, Internal surface modification of MFI-type zeolite membranes for high selectivity and high flux for hydrogen. Langmuir 25 (2009) 4848-4852.

[26] Y. Gu, S.T. Oyama, High molecular permeance in a poreless ceramic membrane. Adv. Mater. 19 (2007) 1636-1640.

[27] M.J. Denexter, J.C. Jansen, H. Vanbekkum, Separation of permanent gases on the all-silica 8-ring clathrasil DD3R. Stud. Surf. Sci. Catal. 84 (1994) 1159-1163. 


\section{DDR-Type Zeolite Membrane Synthesis, Modification and Gas Permeation Studies}

Shaowei Yang, Zishu Cao, Antonios Arvanitis, Xinhui Sun, Zhi Xu, Junhang Dong

DDR-type zeolite membrane has been synthesized using a ball-milled Sigmal-1 zeolite seed layer and subsequently modified for defect repair for high performance in $\mathrm{CO}_{2}$ separation.
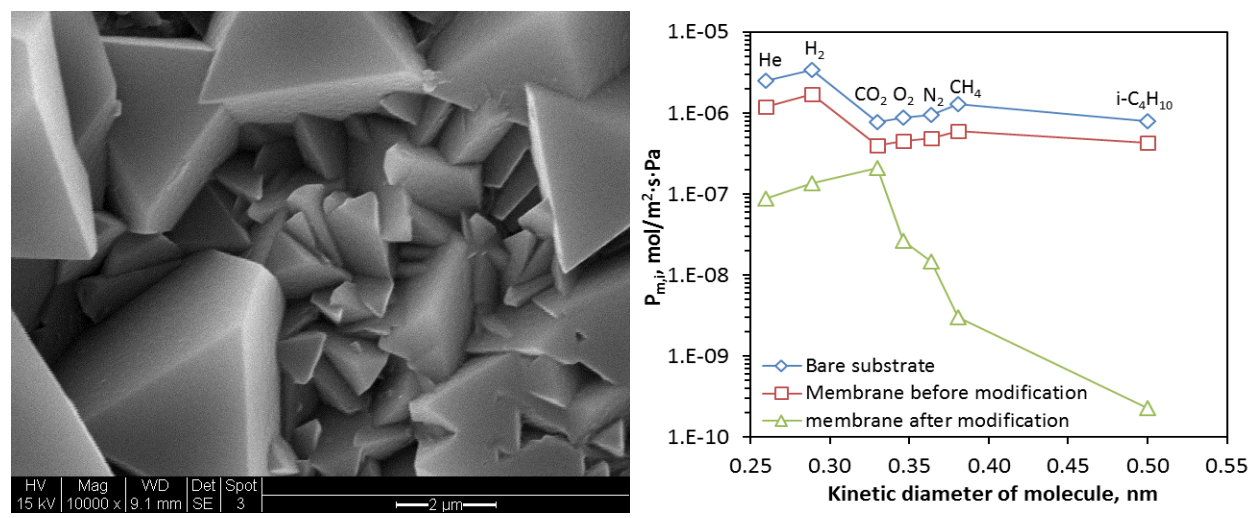